Revista Brasil. Bot., V.28, n.4, p.773-783, out.-dez. 2005

\title{
Fatores de risco à produção de sementes de Ipomoea pes-caprae ${ }^{1}$
}

\author{
TÂNIA TARABINI CASTELLANI ${ }^{2,4}$ e FLAVIO A. MAËS DOS SANTOS ${ }^{3}$
}

(recebido: 28 de agosto de 2003; aceito: 3 de novembro de 2005)

\begin{abstract}
Pre-dispersal hazards and seed production in Ipomoea pes-caprae). We analyzed factors that affect Ipomoea pes-caprae (L.) R. Br. (Convolvulaceae) seed production within the vegetation of 10 beaches on Santa Catarina Island, state of Santa Catarina, Brazil. Ipomoea pes-caprae is a self-incompatible reptant psamophyte, with long stolons. Thus, genets are difficult to distinguish in the field. We therefore monitored patches of Ipomoea pes-caprae, defined as discontinuous areas, colonized by the plant. Abortion occurred in $9.4 \%$ to $76.0 \%$ of the inflorescences of all sites. Abortion after flowering was the major cause of these losses, probably due to ineffective pollination. Sand burrowing had damaged buds and fruits. Seed predation by larvae of the bruchids Megacerus baeri and M. reticulatus and by caterpillars of the moth Ephestia kuhniella was expressive. The bruchids had laid their eggs on fruits near maturation and had damaged as much as $65.7 \%$ of the seeds. Ephestia kuhniella damaged up to $57.4 \%$ of seeds in 1996, but only 5.4\% in 1997, a year with lower fruit abundance. Fruits damaged by the moth did not open in order to disperse their seeds and remained attached to the plant for about three and a half months. The seeds not attacked by the moth were viable, and their seedling survival was similar to that of uninfested fruits. The types of damage observed were capable of reducing the viable seeds of Ipomoea pes-caprae to $9.0 \%$ of the total production. Densities from 0.5 to 30.6 viable seeds $\mathrm{m}^{-2}$ were estimated, with the highest densities in patches with a greater abundance of fruit. We therefore concluded that a strategy of high fruit production might prove to be advantageous. The low density of viable seeds in some locations could represent a limitation on local regeneration.
\end{abstract}

Key words - coastal dunes, seed predation, seed production, pre-dispersal hazards

RESUMO - (Fatores de risco à produção de sementes de Ipomoea pes-caprae). Fatores de risco que afetam a produção de sementes em Ipomoea pes-caprae (L.) R. Br. (Convolvulaceae) foram avaliados em 10 praias da Ilha de Santa Catarina, SC. Ipomoea pes-caprae é auto-incompatível, possui longos estolões, com difícil individualização dos genetas em campo. Assim, manchas de I. pes-caprae foram monitoradas, sendo definidas como áreas ocupadas pela espécie, descontínuas entre si. Nestas, 9,4\% a 76,0\% das inflorescências estavam abortadas. Soterramentos causaram perda de botões e frutos, mas a ineficiência de polinização parece explicar a grande taxa de abortos após a floração. A predação de sementes pelas larvas dos bruquídeos Megacerus baeri e M. reticulatus e por lagartas da mariposa Ephestia kuhniella foi expressiva. Os bruquídeos ovipõem preferencialmente em frutos em amadurecimento, danificando até $65,7 \%$ das sementes produzidas nas manchas. Ephestia kuhniella danificou até 57,4\% das sementes em 1996 e até 5,4\% em 1997, ano com menor abundância de frutos. Frutos com mariposa não abrem para dispersão, permanecendo três meses e meio presos à planta. As sementes intactas destes frutos são viáveis e com sobrevivência de plântulas similar às provindas de frutos sem infestação. Os danos registrados podem reduzir as sementes viáveis a $9 \%$ do total produzido, estimando-se de 0,5 a 30,6 sementes viáveis $\mathrm{m}^{-2}$ nas manchas estudadas. As maiores densidades de sementes viáveis ocorreram nas manchas com mais frutos, reforçando como vantajosa, uma alta produção de frutos. A baixa densidade de sementes viáveis encontradas em algumas localidades talvez possa comprometer a regeneração local da espécie.

Palavras-chave - dunas costeiras, predação de sementes, produção de sementes, riscos de pré-dispersão

\section{Introdução}

A ineficiência de polinização e a limitação de recursos podem causar baixas taxas de formação de

1. Parte da tese de doutorado da $1^{\mathrm{a}}$ autora, Universidade Estadual de Campinas.

2. Universidade Federal de Santa Catarina, Centro de Ciências Biológicas, Departamento de Ecologia e Zoologia, Caixa Postal 476, 88040-900 Florianópolis, SC, Brasil.

3. Universidade Estadual de Campinas, Instituto de Biologia, Departamento de Botânica, Caixa Postal 6109, 13083-970 Campinas, SP, Brasil.

4. Autor para correspondência: ttcastel@ccb.ufsc.br frutos e sementes em populações de dunas (Sterk et al. 1982, Zedler et al. 1983, Westelaken \& Maun 1985, Cordazzo \& Davy 1994, Petanidou et al. 1995, Castellani \& d'Eça-Neves 2000). A deficiência de recursos hídricos, por exemplo, pode reduzir a produção de flores e sementes (Sterk et al. 1982, De Jong \& Klinkhamer 1988, Klinkhamer et al. 1988, Cordazzo 1998) e a sobrevivência de indivíduos reprodutivos (Ernst 1981, d'Eça-Neves \& Castellani 1994).

Nos setores de duna frontal, mais sujeitos à ação marinha, a morte de plantas reprodutivas e a interrupção do desenvolvimento das sementes podem ser causadas por tempestades que elevam o nível das ondas (Keddy 
1982). Outro fator que afeta as populações de dunas é a predação de estruturas reprodutivas, que pode causar a perda de flores, frutos e sementes individuais (Wilson 1977, Castellani \& d'Eça-Neves 2000), bem como a morte de plantas reprodutivas inteiras (Watkinson \& Harper 1978). Esses danos podem reduzir a produção de sementes na população (Keddy et al. 1983, Klinkhamer et al. 1988, Costa et al. 1991, Castellani \& d'Eça-Neves 2000) e afetar o recrutamento de plântulas e a densidade populacional (Klinkhamer et al. 1988).

Ipomoea pes-caprae (L.) R. Br. (Convolvulaceae) é uma espécie colonizadora do pós-praia e dunas frontais, em regiões tropicais e temperadas quentes (Hueck 1955, Devall et al. 1991, Devall 1992). É uma espécie perene e estolonífera, que desenvolve um sistema de ramos longos e curtos (Hueck 1955). A espécie apresenta sistema de reprodução autoincompatível do tipo esporofítico, genético e homomórfico (Devall \& Thien 1992). No sul do Brasil, a floração e a frutificação ocorrem nos meses de verão e outono, em períodos com temperatura e pluviosidade altas (Santos \& Arruda 1995). Neste período, também ocorre a expansão de estolões e a produção de ramos curtos e folhas (Castellani 2003).

Estudos sobre esta espécie questionam a importância da reprodução sexuada na manutenção de populações locais, sendo este ponto controvertido e relacionado à predação de sementes na fase de pré-dispersão. Para Hueck (1955), 50\% das sementes da espécie são predadas por insetos, mas a produção numerosa de sementes garante a conservação "in situ". Wilson (1977) observou taxas de até $85 \%$ de sementes predadas e sugeriu que as populações de Ipomoea pes-caprae devem manter-se por propagação vegetativa.

O objetivo deste estudo foi avaliar os tipos de danos durante a floração e frutificação de populações de Ipomoea pes-caprae na Ilha de Santa Catarina e avaliar seus efeitos na produção final de sementes viáveis nas populações.

\section{Material e métodos}

Áreas de estudo - Dez praias da Ilha de Santa Catarina (27 $23^{\circ}$ a $27^{\circ} 52^{\prime} \mathrm{S}$ e $48^{\circ} 21^{\prime}$ a $48^{\circ} 35^{\prime} \mathrm{W}$ ) foram selecionadas para este estudo, estando localizadas em quatro setores distintos. No setor oeste, banhado pelas baías norte e sul e com baixa energia de ondas, Ipomoea pes-caprae (L.) R. Br. ocorre com menor freqüência e a praia estudada foi a Caieira da Barra do Sul, com 214 m de extensão. No setor leste da ilha, voltado diretamente para o oceano e com alta energia de ondas, foram estudadas as praias da Armação, Joaquina,
Galheta e Moçambique, com extensões variando de $1.080 \mathrm{~m}$ a $11.250 \mathrm{~m}$. No sul, onde há poucas praias arenosas, a Praia do Pântano do Sul $(3.900 \mathrm{~m})$ foi monitorada e no setor norte, Daniela, Forte, Jurerê e Lagoinha (885 m a $3.000 \mathrm{~m}$ de extensão) foram escolhidas para o estudo. Os setores norte e sul são considerados de média energia de ondas, condicionados pelos ventos dominantes (Horn Filho et al. 2000, Castellani \& Santos 2005).

Como é difícil a separação dos genetas de Ipomoea pes-caprae em campo, este estudo monitorou três manchas da espécie em cada praia. Definiu-se como manchas, áreas ocupadas pela espécie, descontínuas entre si. Em cada praia, as manchas foram selecionadas sorteando-se três distâncias ao longo da linha de costa.

Condições climáticas - A Ilha de Santa Catarina possui clima mesotérmico úmido, tipo Cfa de Koeppen, com verões quentes e chuvas distribuídas ao longo de todo o ano. A temperatura média mensal é de $21^{\circ} \mathrm{C}$, variando de $16^{\circ} \mathrm{C}$ em julho a $25^{\circ} \mathrm{C} \mathrm{em}$ fevereiro. A média pluviométrica anual é de $1.700 \mathrm{~mm}$, com maiores índices em janeiro e fevereiro e menores índices de junho a agosto (Castellani \& Santos 2005). Em 1996 e 1997, anos em que os dados foram obtidos, foram registrados $1.757,8 \mathrm{~mm}$ e $2.157,5 \mathrm{~mm}$ de chuva, respectivamente, com altos índices de chuva no verão. Em 1997 houve alta concentração de chuvas no mês de janeiro (640 mm) e em 1996 ocorreram déficits hídricos em maio e em novembro. As médias de temperatura mensal variaram de $14{ }^{\circ} \mathrm{C}$ em agosto de $1996 \mathrm{e}$ $18^{\circ} \mathrm{C}$ em julho de 1997 a $25^{\circ} \mathrm{C}$ nos meses de janeiro e fevereiro (Castellani \& Santos 2005).

Monitoramento de estruturas reprodutivas em 1996 - Em 1996, nas dez praias estudadas, uma transecção perpendicular ao mar foi estabelecida em cada mancha de Ipomoea pes-caprae, do início ao fim da ocorrência de ramos. Nestas, quadrados de $1 \mathrm{~m}^{2}$ foram dispostos de forma contínua, sendo contadas as inflorescências com estruturas em desenvolvimento e as inflorescências nas quais todas as estruturas reprodutivas abortaram. Em janeiro, março e dezembro de 1996, as manchas de Ipomoea pes-caprae em floração foram avaliadas quanto à ocorrência de herbívoros e danos às flores, totalizando 41 levantamentos. Cinqüenta flores foram amostradas em cada mancha e, em manchas com menos de 50 flores, todas foram avaliadas.

Um total de 100 frutos maduros (cápsula seca e fechada) foi coletado ao redor de cada transecção, 50 em março e 50 em maio de 1996, em sete praias estudadas. As praias da Caieira da Barra do Sul, Galheta e Forte foram excluídas desta análise pois apenas uma mancha de Ipomoea pes-caprae maturou frutos em cada uma destas localidades. Para avaliar a eclosão de insetos, cada fruto maduro coletado foi mantido em recipiente de plástico ( $3 \mathrm{~cm}$ de diâmetro e $4 \mathrm{~cm}$ de altura) protegido por filó, durante seis meses em laboratório, sob condições de temperatura e umidade relativa não controladas. Após este período, procedeu-se à contagem do número de sementes com e sem danos, tipos de danos e a ocorrência de sementes mal desenvolvidas. A densidade de frutos e 
sementes produzidas nas manchas de Ipomoea pes-caprae foi avaliada em março de 1996. Para isto, contou-se todos os frutos presentes nos quadrados de $1 \mathrm{~m}^{2}$ estabelecidos ao longo das transecções, nas fenofases de frutos em amadurecimento (coloração acastanhada e parcialmente envolto pelas sépalas), fruto maduro (cápsula seca, fechada, de coloração marrom), com sementes em dispersão (cápsula aberta, expondo as sementes) e com sementes já dispersas. A densidade de frutos e sementes $\mathrm{m}^{2}$ foi estimada com base nesse total e na média de sementes produzidas por fruto, que foi obtida pela contagem de sementes em 50 frutos coletados ao redor das transecções.

A viabilidade de sementes sem danos foi verificada diretamente, submetendo-se as sementes às condições de germinação. As sementes foram colocadas em placas de Petri com papel de filtro umedecido com água destilada e mantidas em câmara de cultivo a $25^{\circ} \mathrm{C}$ e $12 \mathrm{~h}$ de luz, durante dois meses. A cada dois dias, as sementes germinadas foram contadas. As sementes apodrecidas foram examinadas quanto à presença de insetos não eclodidos e posteriormente descartadas. As sementes que não germinaram após esses dois meses foram escarificadas com ácido sulfúrico P.A. $(95 \%$ - $98 \%)$ e retornaram à câmara por mais um mês, tempo suficiente para que todas as sementes germinassem. No processo de escarificação, as sementes foram embebidas no ácido por uma hora, sendo posteriormente lavadas em água corrente durante 10 minutos e submersas em solução de água sanitária a $10 \%$ por mais 10 minutos. No caso de frutos com lagartas da mariposa Ephestia kuhniella, um dos predadores de sementes encontrados, as sementes remanescentes sem danos foram avaliadas quanto à germinação e posterior sobrevivência das plântulas. As plântulas $(n=30)$ foram transplantadas para recipientes de plástico individuais ( $5 \mathrm{~cm}$ de diâmetro e $4 \mathrm{~cm}$ de altura), contendo $1,5 \mathrm{~cm}$ de areia, com regas a cada três dias. A sobrevivência das plântulas foi monitorada por quatro semanas, sendo comparada à de plântulas $(\mathrm{n}=30)$ provindas de sementes de frutos sem esse dano. $\mathrm{O}$ experimento foi realizado em laboratório, em bancada exposta à incidência de luz solar e condições de temperatura não controladas. Monitoramento de estruturas reprodutivas em 1997 - Em janeiro de 1997, inflorescências de Ipomoea pes-caprae foram marcadas em três praias, sendo estas Moçambique, Joaquina e Daniela. Cada botão presente nas inflorescências foi monitorado até a maturação do fruto, sendo as sementes coletadas no início da dispersão. A cada amostragem registrou-se (a) a origem de nova estrutura reprodutiva nas inflorescências, (b) as estruturas sobreviventes, (c) a fenofase, se botão floral, flor em antese, fruto verde (da murcha floral até o desenvolvimento inicial do fruto, ainda envolto pelas sépalas), fruto amadurecendo, fruto maduro, fruto com sementes em dispersão e estrutura abortada, (d) o diâmetro dos frutos e, (e) a presença de necroses, de ovos de besouros bruquídeos e outros danos. As amostragens foram inicialmente semanais, passando a quinzenais após a terceira semana de desenvolvimento. O monitoramento persistiu até a dispersão das sementes ou a queda do último fruto maduro. Cada fruto coletado foi mantido por seis meses em laboratório, para registro da eclosão de insetos, com posterior análise das sementes quanto ao grau de desenvolvimento, presença de danos e capacidade de germinação. As manchas de Ipomoea pes-caprae, onde se realizaram os monitoramentos, foram avaliadas quanto à densidade de estruturas reprodutivas em abril de 1997, com procedimento similar ao descrito para o ano de 1996.

Análise estatística - Testes de Kruskal-Wallis foram realizados para avaliar as semelhanças das densidades e taxas de danos de estruturas reprodutivas obtidas nas diferentes praias. Correlações de Spearman foram feitas para verificar as relações entre algumas destas variáveis. Testes de $\chi^{2}$ foram empregados na análise de sobrevivência de plântulas, sucesso de germinação e ocorrência de abortos (Zar 1999). Os cálculos foram realizados com o Programa Statistica for Windows, versão 5.0, StatSoft, Inc., 1984-1995.

\section{Resultados}

Monitoramento de estruturas reprodutivas em 1996 Nem todas as manchas de Ipomoea pes-caprae (L.) $\mathrm{R}$. Br. amostradas por praia mostraram-se reprodutivas e, naquelas em reprodução, a densidade de inflorescências variou de 0,6 a $50,0 \mathrm{~m}^{-2}$ (tabela 1 ). Manchas mais densas ocorreram nas praias da Armação, Lagoinha e Caieira da Barra do Sul e as menos densas no Forte. As taxas de inflorescências abortadas variaram de $7,6 \%$ a 76,0\% (tabela 1 ), não mostrando correlação significativa às densidades de inflorescências presentes $\left(r_{s}=-0,06 ; P>0,05 ; n=27\right)$. As taxas de aborto mostraram grande variação entre manchas de uma mesma praia, não se observando diferenças entre as localidades estudadas (tabela 1). Alguns danos observados em campo foram causados pela ação marinha e pela herbivoria. Nas praias da Daniela, Armação e Joaquina, 25\%, 35\% e 20\% das inflorescências abortadas em uma das manchas, respectivamente, estavam em ramos retorcidos pelo mar. Na Praia da Galheta, a predação por ninfas de gafanhoto foi observada, com danos evidentes em $50 \%$ das inflorescências de uma das manchas. Das 42 espécies de Arthropoda (Insecta $=40$ espécies e Arachnida $=2$ espécies) amostradas nas avaliações de flores, apenas as ninfas de gafanhoto (Orthoptera) e os besouros Chelymorpha constellata (Chrysomelidae) e Scarabaeidae não identificado foram vistos danificando flores. Os gafanhotos ocorreram em seis praias e em 24,4\% dos 41 levantamentos feitos. Indivíduos de Scarabaeidae e Chelymorpha constellata ocorreram, 
Tabela 1. Manchas de Ipomoea pes-caprae (L.) R. Br. amostradas em reprodução e valores mínimos e máximos de densidade de inflorescências e porcentagem de abortos em março de 1996, em praias da Ilha de Santa Catarina, SC. H = valores obtidos no teste de Kruskal-Wallis.

Table 1. Patches of Ipomoea pes-caprae (L.) R. Br. in reproduction, minimum and maximum values of inflorescence densities, and percentage of abortion registered in March 1996 at beaches of Santa Catarina Island, SC. H = Kruskal-Wallis test values.

\begin{tabular}{|c|c|c|c|}
\hline Praias & Manchas reprodutivas & Inflorescências.m ${ }^{-2}$ & Inflorescências abortadas (\%) \\
\hline Lagoinha & 3 & $18,1-34,0$ & $14,1-27,7$ \\
\hline Jurerê & 3 & $0,6-15,4$ & $16,7-66,7$ \\
\hline Forte & 2 & $1,2-4,9$ & $14,3-33,3$ \\
\hline Daniela & 3 & $5,9-29,0$ & $16,9-72,9$ \\
\hline Caieira da Barra do Sul & 2 & $11,0-50,0$ & $72,7-76,0$ \\
\hline Pântano do Sul & 3 & $2,3-15,9$ & $9,4-17,4$ \\
\hline Armação & 3 & $23,4-31,3$ & $26,9-37,7$ \\
\hline Joaquina & 3 & $1,5-10,5$ & $15,2-53,3$ \\
\hline Galheta & 2 & $3,4-7,1$ & $8,8-50,7$ \\
\hline Moçambique & 3 & $7,9-17,9$ & $7,6-11,4$ \\
\hline $\mathrm{H}_{9,27}$ & & 17,35 & 14,05 \\
\hline $\mathrm{p}^{,, 27}$ & & 0,04 & 0,12 \\
\hline
\end{tabular}

respectivamente, em quatro e duas praias, sendo registrados em $17,1 \%$ e em $4,9 \%$ dos levantamentos $(n=41)$.

Dos frutos maduros coletados, observou-se a eclosão de Megacerus baeri e Megacerus reticulatus (Coleoptera: Bruchidae), ambos com larvas que se desenvolvem dentro das sementes, originando um adulto por semente ou, excepcionalmente, dois. Adultos das duas espécies ocorreram num mesmo fruto. Observou-se que os frutos com danos por bruquídeos abrem-se normalmente para a dispersão de sementes, ocorrendo a eclosão do adulto tanto do fruto maduro fechado, do fruto aberto com sementes em dispersão ou da semente depositada ao solo. Os besouros adultos foram observados comendo pólen de Ipomoea pes-caprae, sendo registrados em nove praias e $75,6 \%$ dos levantamentos feitos para a avaliação de flores $(\mathrm{n}=41)$. Também foi registrada a eclosão de Ephestia kuhniella (Lepidoptera: Pyralidae), com uma lagarta por fruto maduro, que pode consumir ou não todas as sementes presentes. A lagarta empupa no fruto, entre as sementes residuais. $\mathrm{O}$ casulo tecido apresenta-se aderido à parede interna do fruto e o adulto emerge por um orifício neste ponto de fixação. Esses frutos não abrem para dispersão e permanecem bem fechados, mesmo após a eclosão da mariposa. Predação por Megacerus spp. pode ocorrer em frutos com mariposa.
Danos causados pelas espécies de Megacerus e por Ephestia kuhniella ocorreram nas sete praias e nas 19 manchas avaliadas, com maior proporção de danos pela mariposa. A proporção de frutos com Ephestia kuhniella variou de $1,8 \%$ a $82,0 \%$ e com bruquídeos de $1,0 \%$ a $52,0 \%$, com perdas de até $57,4 \%$ e $30,1 \%$ das sementes produzidas, respectivamente (tabela 2). A ocorrência de frutos e sementes com bruquídeos não foi a mesma para todas as localidades, registrando-se valores muito baixos nas praias da Daniela e Lagoinha (tabela 2). Em parte, tais diferenças podem estar relacionadas à ocorrência da mariposa, uma vez que os dois tipos de dano estiveram negativamente correlacionados $\left(\mathrm{r}_{\mathrm{s}}=-0,71 ; \mathrm{n}=19 ; \mathrm{P}<0,05\right.$ para frutos; $r_{s}=-0,67 ; n=19 ; P<0,05$ para sementes). Observou-se também, uma tendência de maior ocorrência de mariposas em manchas com maior densidade de frutos e sementes $\left(r_{s}=0,47 ; n=19 ; \mathrm{P}<0,05\right.$ para frutos; $\mathrm{r}_{\mathrm{s}}=0,48 ; \mathrm{n}=19 ; \mathrm{P}<0,05$ para sementes).

Das sementes de Ipomoea pes-caprae, também eclodiram três espécies de Hymenoptera, das famílias Chalcididae, Eulophidae e Eupelmidae, supostamente parasitas dos bruquídeos ou da mariposa. Sementes com estes Hymenoptera ocorreram em todas as praias, com baixa frequiência. Houve diferenças significativas quanto à presença de vespas nas praias (tabela 2), sendo sugerida uma relação mais estreita destes parasitas com os bruquídeos, pois suas ocorrências aumentaram com a 
dos besouros $\left(\mathrm{r}_{\mathrm{s}}=0,65 ; \mathrm{P}<0,05 ; \mathrm{n}=19\right)$ e não com a ocorrência da mariposa $\left(\mathrm{r}_{\mathrm{s}}=-0,21 ; \mathrm{P}>0,05 ; \mathrm{n}=19\right)$. Além dos danos causados pelos insetos, foram observadas muitas sementes murchas, ocas e com fungos, com maiores taxas nas praias da Joaquina e Armação (tabela 2), onde alguns ramos estavam danificados pelo mar.

Após avaliar a viabilidade das sementes sem danos, estimou-se, para as manchas de Ipomoea pes-caprae estudadas, uma viabilidade entre $9,6 \%$ e $55,0 \%$ das sementes produzidas, com densidades variando de 0,5 a 30,6 sementes viáveis $\mathrm{m}^{-2}$ (tabela 2). As maiores densidades de sementes viáveis ocorreram nas manchas com maior produção de frutos $\left(\mathrm{r}_{\mathrm{s}}=0,75 ; \mathrm{P}<0,05\right.$; $\mathrm{n}=19)$.

As sementes que permaneceram intactas em frutos com mariposa estavam na maioria viáveis $(93,0 \%$; $\mathrm{n}=57)$ e com taxa de viabilidade similar $\left(\chi^{2}=1,75\right.$; $\mathrm{gl}=1 ; \mathrm{P}>0,05)$ à de sementes de frutos sem mariposa $(87,4 \% ; \mathrm{n}=222)$. Das sementes analisadas, a porcentagem que germinou sem escarificação foi semelhante $\left(\chi^{2}=2,67 ; \mathrm{gl}=1 ; \mathrm{P}>0,05\right)$ para sementes provindas de frutos com $(52,6 \% ; \mathrm{n}=57)$ e sem este tipo de dano $(37,4 \% ; n=222)$. Quanto à sobrevivência inicial das plântulas, esta também não diferiu em função da origem das sementes $\left(\chi^{2}=0,63 ; \mathrm{gl}=1 ; \mathrm{P}>0,05\right)$, sendo registrado $56,7 \%(\mathrm{n}=30)$ e $70 \%(\mathrm{n}=30)$ de sobrevivência, após 4 semanas, para plântulas provindas de frutos com e sem mariposa, respectivamente.

Monitoramento de estruturas reprodutivas em 1997 Nas inflorescências monitoradas, botões e flores ocorreram de janeiro a meados de abril. Frutos verdes ocorreram de janeiro ao final de maio e frutos amadurecendo de janeiro a junho. Frutos verdes apresentaram valores máximos em janeiro ou fevereiro e frutos amadurecendo mostraram picos em fevereiro ou março, dependendo da praia (figura 1). Frutos maduros fechados e frutos com sementes em dispersão ocorreram de meados de fevereiro até junho.

A porcentagem de inflorescências que produziu frutos variou de $42,6 \%$ a $59,5 \%$ (tabela 3 ) e diferiu significativamente entre as praias $\left(\chi^{2}=15,49 ; \mathrm{gl}=2\right.$; $\mathrm{P}<0,001)$, com maiores perdas na Daniela. O número de estruturas reprodutivas por inflorescência variou de 1 a 13, com produção de 1 a 5 frutos e de 1 a 4 sementes por fruto (tabela 3). A maioria dos abortos se deu na fase de fruto verde (tabela 4). Soterramentos causaram a morte de botões e frutos verdes nas praias da Joaquina e Daniela, em janeiro e início de fevereiro. Na Joaquina, os soterramentos decorreram de ação marinha e na Daniela, de ação eólica. Cerca de 17,5\% dos abortos

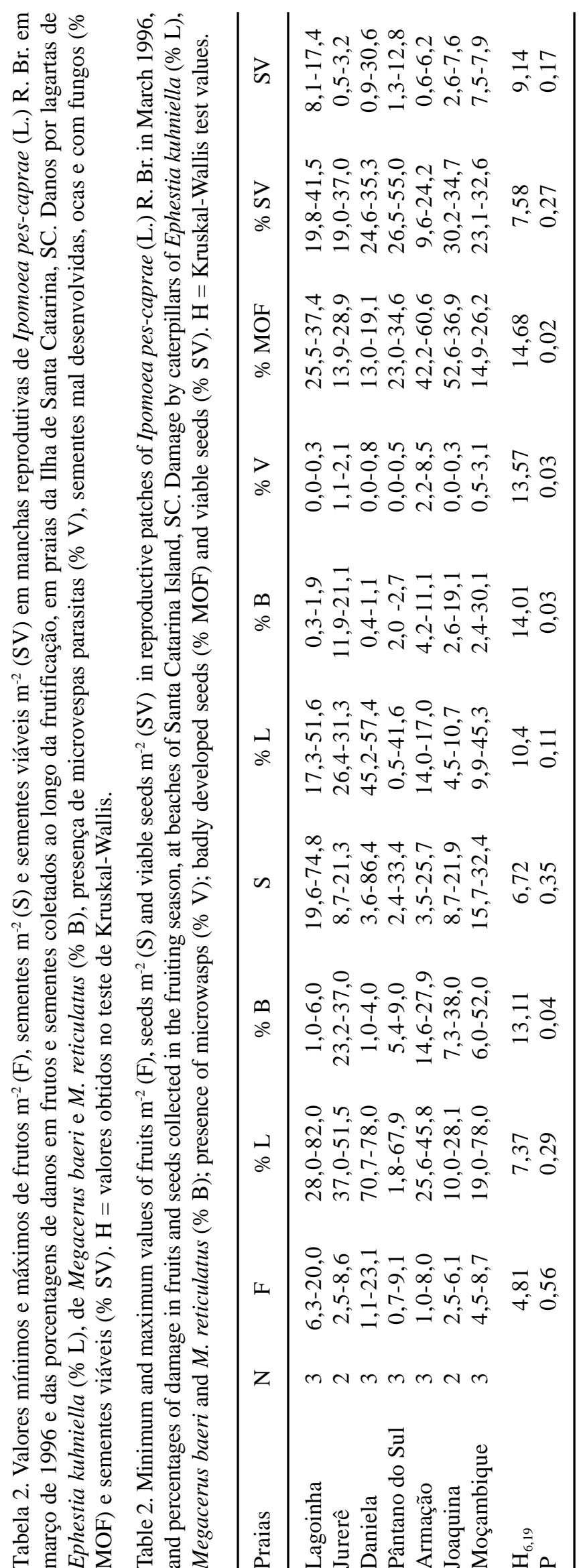


registrados em botão $(n=120)$ e $5,1 \%$ dos registrados em fruto verde $(n=765)$ ocorreram em estruturas soterradas. Abortos de frutos em amadurecimento foram poucos (tabela 4$)$ e $23,8 \%$ destes $(n=21)$ ocorreram associados a soterramentos. Quando soterrados, os frutos tornam-se amarelados e muitos apodrecem. Dois frutos abortados $(9,5 \%)$ estavam danificados pelo besouro Scarabaeidae.

Frutos com Ephestia kuhniella ocorreram nas três praias, mas em menor taxa em relação aos frutos
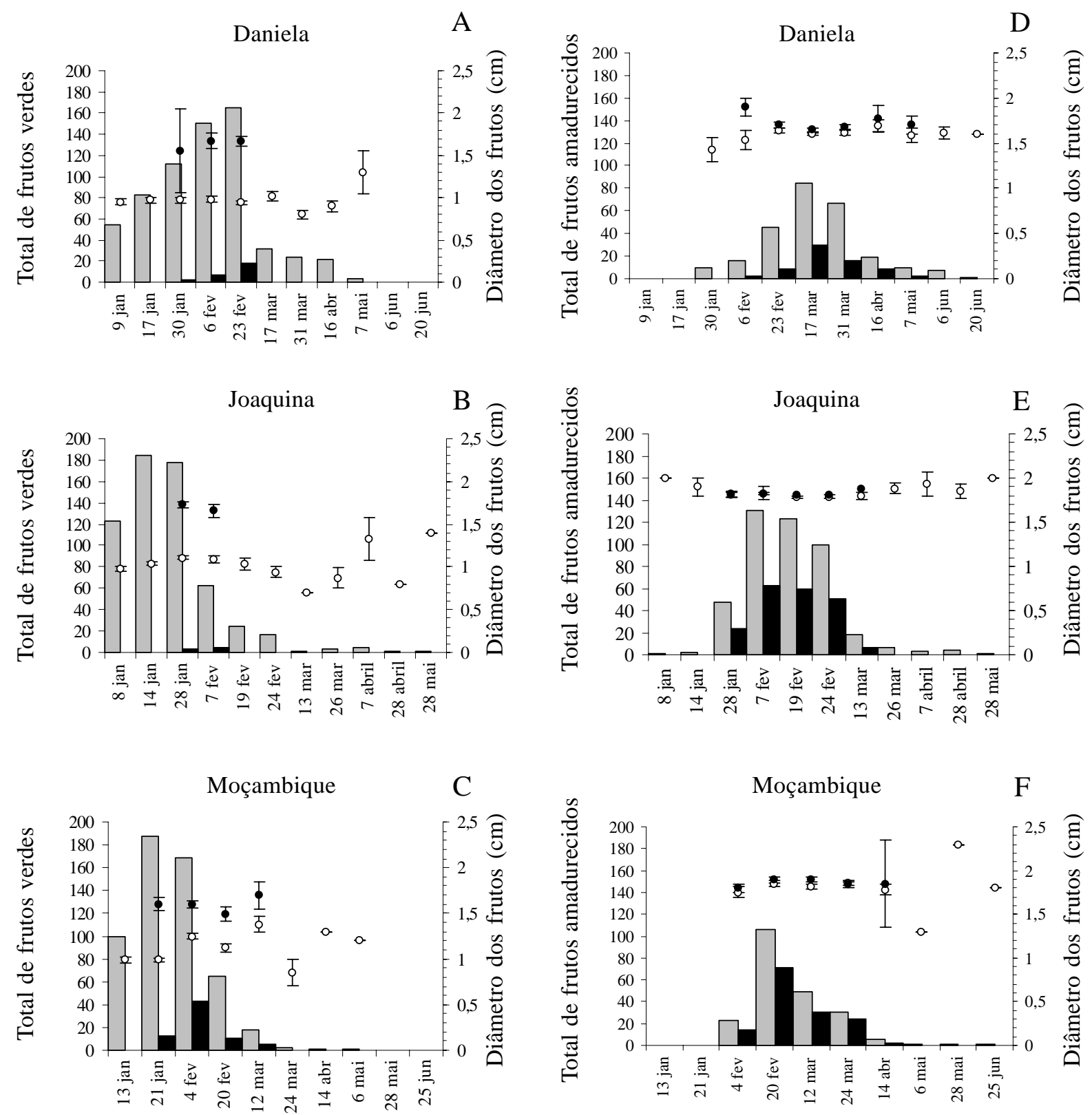

Figura 1. Número de frutos de Ipomoea pes-caprae (L.) R. Br. em fase de fruto verde (A, B, C) e em amadurecimento (D, E, F) (barra cinza) e número de frutos com oviposição de duas espécies de Megacerus (barra preta), em três praias da Ilha de Santa Catarina, SC, no verão de 1997. Os diâmetros médios \pm erro padrão dos frutos disponíveis (O) e utilizados $(\bullet)$ pelos besouros são mostrados para cada data.

Figure 1. Numbers of Ipomoea pes-caprae (L.) R. Br. fruits in immature (A, B, C) and ripening (D, E, F) phases (gray bar), and number of fruits with eggs laid by two species of Megacerus (black bar) at three beaches on Santa Catarina Island, SC, summer 1997. The mean diameter \pm standard error of fruits available $(\bigcirc)$ and fruits used $(\bullet)$ by bruchids are shown for each date. 
Tabela 3. Número de inflorescências monitoradas, valores mínimos e máximos de estruturas reprodutivas, porcentagem de inflorescências que produziu frutos e que abortaram e valores mínimos e máximos do número de frutos maturados por inflorescência e de sementes produzidas por fruto em inflorescências de Ipomoea pes-caprae (L.) R. Br. monitoradas no verão de 1997, em três praias da Ilha de Santa Catarina, SC.

Table 3. Percentages of inflorescence that developed fruits, minimum and maximum values of reproductive structures and seeds produced in Ipomoea pes-caprae (L.) R. Br. during the summer of 1997, at three beaches on Santa Catarina Island, SC.

\begin{tabular}{lccc}
\hline & Daniela & Joaquina & Moçambique \\
\hline Inflorescências monitoradas & 331 & 234 & 205 \\
Estruturas reprodutivas/inflorescência & $1-8$ & $1-13$ & $1-6$ \\
Inflorescências que maturaram frutos (\%) & 42,6 & 53,0 & 59,5 \\
Inflorescências que abortaram (\%) & 57,4 & 47,0 & 40,5 \\
Frutos maturados por inflorescência & $1-4$ & $1-5$ & $1-4$ \\
Número de sementes por fruto & $1-4$ & $1-4$ & $1-6^{*}$ \\
\hline
\end{tabular}

danificados por bruquídeos (tabela 5). Estes frutos permaneceram fechados e presos às inflorescências por três meses e meio, enquanto frutos maduros sem este dano abriram a cápsula seca poucos dias após a maturação. Os danos causados pela mariposa em sementes também foram baixos (tabela 5). Frutos com Megacerus baeri $\mathrm{e}$. reticulatus foram mais freqüentes, com maiores taxas na Praia de Moçambique. Os bruquídeos acarretaram perdas de até $65,7 \%$ das sementes produzidas (tabela 5).

Sementes com microvespas parasitas (Hymenoptera) foram raras e sementes murchas, ocas ou com fungos geraram perdas de até $24,4 \%$ das sementes produzidas. Assim, sementes viáveis representaram de 9,5\% a 69,8\% do total produzido, com menores taxas em Moçambique e maiores na Daniela (tabela 5). Com base nestas taxas, podemos estimar que de 29,0 sementes $\mathrm{m}^{-2}$ produzidas na praia da Daniela e 18,6 sementes $\mathrm{m}^{-2}$ na Joaquina,
20,2 sementes $\mathrm{m}^{-2}$ e 11,9 sementes $\mathrm{m}^{-2}$, respectivamente, são viáveis. Em Moçambique, com baixa densidade de sementes nas áreas estudadas, de 5,9 sementes $\mathrm{m}^{-2}$ produzidas, apenas $0,6 \mathrm{~m}^{-2}$ são viáveis.

Fêmeas de Megacerus baeri e $M$. reticulatus foram observadas ovipondo, sendo os ovos de M. baeri amarelos e os de $M$. reticulatus de tom verde muito forte. Estes ovos perdem a coloração posteriormente, tornando-se difícil sua diferenciação. Assim, com base na coloração amarela ou verde, verificou-se maior ocorrência de ovos de $M$. baeri $(91,3 \%$; $\mathrm{n}=115)$ na Praia da Joaquina. A ocorrência de ovos das duas espécies foi equivalente na Praia da Daniela (M. baeri: 53,3\%; $M$. reticulatus: $46,7 \% ; \mathrm{n}=60$ ) e na Praia de Moçambique (M. baeri: 54,2\%; M. reticulatus: 45,8\%; $\mathrm{n}=445$ ). Houve maior número de ovos depositados em frutos amadurecendo, tanto para $M$. baeri $(81,2 \% ; \mathrm{n}=378)$ como para $M$. reticulatus $(70,2 \% ; \mathrm{n}=242)$ e,

Tabela 4. Total de estruturas reprodutivas de Ipomoea pes-caprae (L.) R. Br. que atingiu a fase de fruto maduro e porcentagem de abortos em cada fenofase, em três praias da Ilha de Santa Catarina, SC.

Table 4. Reproductive structures which produced mature fruits and percentages of abortion in each phase of development of Ipomoea pes-caprae (L.) R. Br., monitored at three beaches on Santa Catarina Island, SC.

\begin{tabular}{lccc}
\hline Estruturas reprodutivas & Daniela & Joaquina & Moçambique \\
\hline Total monitorado & 654 & 458 & 433 \\
Amadureceram fruto (\%) & 27,5 & 39,7 & 40,0 \\
Abortaram (\%) & 72,5 & 60,3 & 60,0 \\
em botão (\%) & 11,4 & 13,4 & 11,1 \\
em fruto verde (\%) & 83,1 & 69,9 & 68,5 \\
em fruto amadurecendo (\%) & 1,5 & 1,4 & 3,8 \\
anteriores ao monitoramento (\%) & 4,0 & 15,2 & 16,5 \\
\hline
\end{tabular}


Tabela 5. Densidade de frutos e sementes de Ipomoea pes-caprae (L.) R. Br. e ocorrência de danos e mau desenvolvimento em frutos e sementes de inflorescências monitoradas no verão de 1997, em três praias da Ilha de Santa Catarina, SC. DL são danos por lagartas de Ephestia kuhniella e DB são danos causados por duas espécies de bruquídeos, Megacerus baeri e M. reticulatus.

Table 5. Density of fruits and seeds of Ipomoea pes-caprae (L.) R. Br. and the occurrence of damage and bad development in fruits and seeds of inflorescences monitored during the summer of 1997, at three beaches on Santa Catarina Island, SC. DL refers to damage caused by Ephestia kuhniella and DB refers to damage caused by Megacerus baeri and M. reticulatus.

\begin{tabular}{lccc}
\hline & Daniela & Joaquina & Moçambique \\
\hline Densidade de frutos (número.m ${ }^{-2}$ ) & 10,2 & 5,2 & 1,5 \\
Total de frutos monitorados & 180 & 182 & 173 \\
\% com danos de mariposa (DL) & 1,1 & 0,5 & 4,6 \\
\% com danos de bruquídeos (DB) & 22,2 & 37,4 & 86,1 \\
\% sem danos aparentes & 76,7 & 62,1 & 9,2 \\
Densidade de sementes (número. m $^{-2}$ ) & 29,0 & 18,6 & 5,9 \\
Total de sementes nos frutos monitorados & 401 & 599 & 565 \\
\% com danos de mariposa (DL) & 1,7 & 0,7 & 5,4 \\
\% com danos de bruquídeos (DB) & 10,5 & 17,7 & 65,7 \\
\% de sementes murchas, ocas e mofadas (MOF) & 17,9 & 17,0 & 24,4 \\
\% com microvespas parasitas (DV) & 0,0 & 0,5 & 0,2 \\
\% de sementes viável & 69,8 & 64,1 & 9,5 \\
\hline
\end{tabular}

secundariamente, em frutos verdes (M. baeri: 18,0\%; $M$. reticulatus: $28,5 \%$ ). Houve poucos registros de ovos em frutos maduros. As posturas de M. baeri ocorreram principalmente no ovário em desenvolvimento $(97 \%$; $\mathrm{n}=378$ ). As posturas de $M$. reticulatus ocorreram de forma equivalente no ovário $(49,6 \% ; \mathrm{n}=242)$ e na porção inferior do estilete seco $(49,2 \%)$, ocorrendo algumas posturas no pedicelo do fruto.

Nos frutos verdes e amadurecendo, ovos de Megacerus foram observados de janeiro a maio, aumentando em número quando mais frutos entraram em amadurecimento (figura 1). Em frutos amadurecendo, os picos de infestação ocorreram em fevereiro na Joaquina e Moçambique e em março na Daniela (figura 1). Nesses picos, a maior proporção de frutos com ovos ocorreu em Moçambique, atingindo valores de 67,0\% $(n=106)$. Na Joaquina, os valores atingiram $48,1 \%(n=131)$ e na Daniela, $35,3 \%(n=85)$. Nos momentos de pico, os frutos em amadurecimento com postura tinham cerca de 1,4 ovos na Daniela, 1,4 na Joaquina e 4,6 em Moçambique. Em Moçambique observou-se até 19 ovos por fruto e nas duas outras praias observou-se de 3 a 4 ovos, no máximo.

Nos frutos verdes, as posturas ocorreram em frutos de maior diâmetro (figura 1). Nas praias com maior infestação, os frutos verdes foram proporcionalmente mais utilizados, tendo-se um uso de $25,0 \%$ em
Moçambique, $10,1 \%$ na Daniela e $7,9 \%$ na Joaquina, nos momentos de maior infestação. Nos frutos em amadurecimento, a média de tamanho dos frutos usados para postura esteve entre 1,6 e 1,9 cm, mais similar ao tamanho dos frutos disponíveis nas populações (figura 1).

\section{Discussão}

A herbivoria por gafanhotos, o soterramento e a ação do mar foram os principais causadores de danos a botões e frutos verdes de Ipomoea pes-caprae (L.) R. Br. A herbivoria de flores e de frutos por gafanhotos já foi relatada para outras populações de Ipomoea pescaprae (Wilson 1977, Devall et al. 1991), sendo registrada no presente estudo como causadora de perdas bastante acentuadas, porém de forma bastante localizada. Por outro lado, o soterramento de botões e de frutos verdes, causado tanto por ação eólica como marinha, não é referido como agente de dano a estruturas reprodutivas em outras espécies de dunas (Sterk et al. 1982, Zedler et al. 1983, Westelaken \& Maun 1985, Cordazzo \& Davy 1994, Petanidou et al. 1995, Castellani \& d'Eça-Neves 2000). Apenas Keddy (1982) referiuse à ação marinha, uma vez que as tempestades de outono matam as plantas reprodutivas e interrompem o desenvolvimento dos frutos em Cakile edentula (Bigel.) Hook. Danos desse tipo, no entanto, não ocorreram em 
todas as praias estudadas, sendo mais expressivos nas praias da Armação, Daniela e Joaquina, que sofreram acentuada erosão em 1996 (Castellani 2003).

As maiores taxas de aborto em Ipomoea pes-caprae foram na fase de frutos verdes, que neste estudo englobou da murcha floral até o desenvolvimento inicial do fruto. Estas taxas, de até $83 \%$, não podem ser explicadas apenas por predação, soterramento e dano pelo mar. Como Ipomoea pes-caprae é auto-incompatível (Devall \& Thien 1992), sugere-se que certa limitação por polinização possa estar atuando. Um outro fator que poderia explicar estas perdas e reduzir as taxas de formação de frutos seria uma limitação de recursos, sugerida para outras plantas de duna (Sterk et al. 1982, Zedler et al. 1983, Westelaken \& Maun 1985, Petanidou et al. 1995, Castellani \& d'Eça-Neves 2000). No caso de Ipomoea pes-caprae, neste estudo, não há evidências que sustentem uma hipótese de limitação de recursos, pois as taxas de inflorescências abortadas não mostraram relação com a densidade de inflorescências em desenvolvimento nas manchas.

Frutos em amadurecimento tiveram baixas taxas de aborto. É nesta fase de desenvolvimento que ocorre, preferencialmente, a postura de ovos das duas espécies de bruquídeos encontradas, o que as enquadra numa "guilda de frutos maduros" (Johnson \& Romero 2004). Estes bruquídeos e uma espécie de mariposa foram os principais causadores de danos a sementes de Ipomoea pes-caprae, não havendo referências a larvas de mariposas como predadoras de sementes dessa espécie (Devall 1992). Estes danos ocorreram em todas as praias, nos dois anos estudados, mostrando variação de intensidade entre anos e locais. Os bruquídeos ora registrados, Megacerus baeri e $M$. reticulatus nunca foram relatados como parasitas de Ipomoea pes-caprae, sendo este o primeiro registro. São referidas como parasitas de Ipomoea pes-caprae as seguintes espécies: Megacerus leucospilus na Costa Rica, Golfo do México e Havaí (Wilson 1977, Devall \& Thien 1989, Devall et al. 1991), Megacerus coryphae no Golfo do México (Devall \& Thien 1989) e Megacerus pescaprae no Brasil e México (Teran \& Kingsolver 1977). Por outro lado, Megacerus baeri e $M$. reticulatus são referidos como parasitas de outras espécies de Convolvulaceae (Teran \& Kingsolver 1977).

Na Ilha de Santa Catarina, a ocorrência de danos por Megacerus spp. em frutos atingiu valores de até $86 \%$, com perdas de até $66 \%$ das sementes. Hueck (1955) referiu-se a perdas de $50 \%$ das sementes de Ipomoea pes-caprae por insetos, mas sugeriu que a elevada produção de sementes permite a conservação "in situ".
Wilson (1977) registrou perdas de $15 \%$ a $85 \%$ de sementes por bruquídeos na Costa Rica e sugeriu que estas populações devam manter-se por propagação vegetativa. Devall et al. (1991), no Havaí, encontraram $47 \%$ das sementes danificadas por bruquídeos. No Golfo do México, Devall \& Thien (1989) registraram danos de $3,6 \%$ a $16 \%$, sendo os danos ausentes em algumas praias. Apesar do sugerido por Hueck (1955), há áreas na Ilha de Santa Catarina onde a produção de frutos de Ipomoea pes-caprae é baixa e, nestes casos, a predação por bruquídeos pode reduzir a valores muito pequenos a produção de sementes viáveis, como o ocorrido na Praia de Moçambique em 1997. Assim, alta taxa de parasitismo por bruquídeos associada a baixa produção de frutos pode representar um fator limitante à regeneração de Ipomoea pes-capraae em algumas praias da Ilha de Santa Catarina.

A coleta de frutos maduros (cápsulas secas e fechadas) indicou taxas de dano muito altas em 1996 por Ephestia kuhniella, se comparadas às obtidas no monitoramento de 1997, que avaliou todos os frutos maturados, tanto os que abriram para dispersão quanto os que permaneceram fechados. Sugere-se que amostragens restritas a frutos maduros podem superestimar a ocorrência de danos por Ephestia kuhniella na população, pois estes frutos não abrem para a dispersão. Não se descarta, no entanto, que exista uma variação anual nas taxas de danos por Ephestia kuhniella. Os verões de 1996 e 1997 foram distintos, com pluviosidade muito alta em janeiro de 1997 (Castellani \& Santos 2005). Tais diferenças podem afetar o desenvolvimento dos insetos, apesar de Ephestia kuhniella apresentar condições de desenvolvimento bem amplas (Jacob \& Cox 1977). Outra possível explicação estaria baseada no fato desta mariposa mostrar maior ocorrência em áreas mais densas. Desse modo, sugerese que a redução de sua ocorrência em 1997 possa estar associada à menor proporção de ramos reprodutivos observada nas Praias da Daniela, Joaquina e Moçambique naquele ano (Castellani \& Santos 2005).

A menor ocorrência de Megacerus spp. em áreas com maior ocorrência de Ephestia kuhniella pode refletir uma interferência da mariposa sobre os besouros. As lagartas de Ephestia kuhniella secretam substâncias que impedem o acesso de co-específicas (Herbison-Evans \& Crossley 2003) e isto pode garantir a presença de uma única lagarta por fruto. Estas substâncias e o consumo das sementes por estas lagartas devem afetar a sobrevivência das larvas destes besouros.

Como os frutos com Ephestia kuhniella ficam mais tempo presos às inflorescências, a dispersão das sementes 
viáveis destes frutos é mais tardia. Isto estabelece para Ipomoea pes-caprae o que Zhang \& Maun (1994) definiram como um banco de sementes aéreo. Muitas espécies de duna têm frutos diferenciados, seja por dimorfismo, localização na inflorescência ou desenvolvimento diferencial, permanecendo mais tempo presos à planta-mãe (Pemadasa \& Lovell 1974, Ernst 1981, 1985, Keddy 1982, Westelaken \& Maun 1985, Zhang \& Maun 1994). Westelaken \& Maun (1985) mostraram que as sementes que ficam presas à plantamãe podem ser pequenas ou vazias, sendo poucas viáveis. Isto não ocorreu em Ipomoea pes-caprae, pois os frutos com Ephestia kuhniella têm sementes remanescentes viáveis e plântulas com chances de sobrevivência similar às provindas de frutos sem este dano.

Além dos danos causados por insetos, Ipomoea pes-caprae mostrou perdas de sementes por mau desenvolvimento, expressivas em algumas localidades. A ação marinha, que pode cessar o desenvolvimento de sementes (Keddy 1982), pode estar atuando em algumas praias. Não se descarta, no entanto, que este mau desenvolvimento possa resultar de uma limitação da planta para maturar todas as sementes. Ipomoea pes-caprae apresenta crescimento vegetativo ativo na estação reprodutiva (Castellani 2003) e, segundo Cordazzo \& Davy (1994), este crescimento pode restringir o desenvolvimento de sementes em plantas de duna.

Os monitoramentos feitos mostraram que os danos em frutos e sementes de Ipomoea pes-caprae podem reduzir as sementes viáveis nestas populações à cerca de $9 \%$ do total de sementes produzidas. Com uma produção estimada entre 2,5 a 86,4 sementes. $\mathrm{m}^{-2}$, em março de 1996, as sementes viáveis de Ipomoea pes-caprae não atingiram densidades acima de 30,6 sementes viáveis. $\mathrm{m}^{-2}$, com menores densidades em torno de 0,5 sementes viáveis. $m^{-2}$. As maiores densidades de sementes viáveis ocorreram nas manchas com maior densidade de frutos, o que reforça, como vantajosa, uma estratégia de alta produção de frutos. Sugere-se que a baixa densidade de sementes viáveis encontradas em algumas localidades talvez possa comprometer a regeneração local da espécie.

Agradecimentos - A C. Ribeiro-Costa (CIIF, UFPR) pela identificação dos besouros bruquídeos; ao CIIF (UFPR) pela identificação dos demais besouros; a K.S. Brown Jr. (IB, Unicamp) pela identificação de Ephestia kuhniella e a B.C. Lopes (CCB, UFSC) pela identificação das vespas. À Capes pela concessão de bolsa PICD a T.T. Castellani. F.A.M. Santos agradece ao Conselho Nacional de Desenvolvimento Científico e Tecnológico (CNPq) pela bolsa de produtividade em pesquisa (207132/2004-8).

\section{Referências bibliográficas}

CASTELLANI, T.T. 2003. Estrutura e dinâmica populacional de Ipomoea pes-caprae na Ilha de Santa Catarina. Tese de doutorado, Universidade Estadual de Campinas, Campinas.

CASTELLANI, T.T. \& D'EÇA-NEVES, F.F. 2000. Population ecology of Paepalanthus polyanthus: predispersal hazards and seed production. Acta Botanica Brasilica 14:317-326.

CASTELLANI, T.T. \& SANTOS, F.A.M. 2005. Abundância de ramos reprodutivos e produção de sementes em populações de Ipomoea pes-caprae na Ilha de Santa Catarina. Acta Botanica Brasilica 19:251-264.

CORDAZZO, C.V. 1998. Biologia de Senecio crassiflorus (Poir.) DC. nas dunas costeiras no sul do Brasil. I. Características reprodutivas. In Anais do IV Simpósio de ecossistemas brasileiros (S. Watanabe, coord.). Aciesp, São Paulo, v.3, p.92-96.

CORDAZZO, C.V. \& DAVY, A.J. 1994. Seed production and seed quality of the dune building grass Panicum racemosum Spreng. Acta Botanica Brasilica 8:193-203.

COSTA, C.S.B., SEELIGER, U. \& CORDAZZO, C.V. 1991. Leaf demography and decline of Panicum racemosum populations in coastal foredunes of southern Brazil. Canadian Journal of Botany 69:1593-1599.

D'EÇA-NEVES, F.F. \& CASTELLANI, T.T. 1994. Fenologia e aspectos reprodutivos de Paepalanthus polyanthus (Bong.) Kunth (Eriocaulaceae) em baixada úmida entre dunas na Praia da Joaquina, Ilha de Santa Catarina, SC. Insula 23:121-149.

DE JONG, T.J. \& KLINKHAMER, P.G.L. 1988. Population ecology of the biennials Cirsium vulgare and Cynoglossum officinale in a coastal sand-dune area. Journal of Ecology 76:366-382.

DEVALL, M.S. 1992. The biological flora of coastal dunes and wetlands. 2. Ipomoea pes-caprae (L.) Roth. Journal of Coastal Research 8:442-456.

DEVALL, M.S. \& THIEN, L.B. 1989. Factors influencing the reproductive success of Ipomoea pes-caprae (Convolvulaceae) around the Gulf of Mexico. American Journal of Botany 76:1821-1831.

DEVALL, M.S. \& THIEN, L.B. 1992. Self-incompatibility in Ipomoea pes-caprae (Convolvulaceae). American Midland Naturalist 128:22-29.

DEVALL, M.S., THIEN, L.B. \& PLATT, W.J. 1991. The ecology of Ipomoea pes-caprae, a pantropical strand plant. In Proceedings of the Symposium on coastal sand dunes. University of Guelph, Ontario, p.231-249. 
ERNST, W.H.O. 1981. Ecological implication of fruit variability in Phleum arenarium L., an annual dune grass. Flora 171:387-398.

ERNST, W.H.O. 1985. Some considerations of and perspectives in coastal ecology. Vegetatio 62:533-545.

HERBISON-EVANS, D. \& CROSSLEY, S. 2003. Ephestia kuehniella Keller, 1879: Mediterranean flour or mill moth. http://linus.socs.edu.au/ don/larvae/pyra/ kuehn.html (acesso em 1/05/2005).

HORN FILHO, N.O., LEAL P.C. \& OLIVEIRA, J.S. 2000. Ilha de Santa Catarina, SC - Brasil: $88 \mathrm{~km}$ de praias arenosas. In Simpósio brasileiro sobre praias arenosas: morfodinâmica, ecologia, usos, riscos e gestão. (A.H.F. Klein, coord.). Editora da Univali, Itajaí, p.164-165.

HUECK, K. 1955. Plantas e formação organogênica das dunas no litoral paulista - Parte 1. Instituto de Botânica, São Paulo.

JACOB, T.A. \& COX, P.D. 1977. The influence of temperature and humidity on the life-cycle of Ephestia kuehniella Zeller (Lepidoptera: Pyralidae). Journal of Stored Products Research 13:107-118.

JOHNSON, C.D. \& ROMERO, J. 2004. Evolution of oviposition guilds in the Bruchidae (Coleoptera). Revista Brasileira de Entomologia 48:401-408.

KEDDY,C.J., KEDDY, P.A. \& PLANCK, R.J. 1983. An ecological study of Cypripedium passerinum Rich. (Sparrow's egg lady-slipper, Orchidaceae) on the north shore of Lake Superior. Canadian Field-Naturalist 97:268-274.

KEDDY, P.A. 1982. Population ecology on an environmental gradient: Cakile edentula on a sand dune. Oecologia 52:348-355.

KLINKHAMER, P.G., DE JONG, T.J. \& MEIJDEN, VAN DER E. 1988. Production, dispersal and predation of seeds in the biennial Cirsium vulgare. Journal of Ecology 76:403-414.

PEMADASA, M.A. \& LOVELL, P.H. 1974. Factors affecting the distribution of some annuals in the dune system at Aberffraw, Anglesey. Journal of Ecology 62:403-416.
PETANIDOU, T.H., DEN NIJS, J.C.M. \& OOSTERMEIJER, J.G.B. 1995. Pollination ecology and constraints on seed set of the rare perennial Gentiana cruciata L. in the Netherlands. Acta Botanica Neerlandica 44:55-74.

SANTOS, C.R. \& ARRUDA, V.L.V. 1995. Floração, predação de flores e frutificação de Ipomoea pes-caprae e I. imperati (Convolvulaceae). Insula 24:15-36.

STERK, A.A., DUIJKAREN, A., VAN HOGERVORST, J. \& VERBEEK, E.D.M. 1982. Demographic studies of Anthyllis vulneraria L. in the Netherlands. II. Population density, fluctuations and adaptations to arid conditions, seed populations, seedling mortality, and influence of the biocenosis on demographic features. Acta Botanica Neerlandica 31:11-40.

TERAN, A.L. \& KINGSOLVER, J.M. 1977. Revisión del genero Megacerus (Coleoptera:Bruchidae). Opera Lilloana 25:1-287.

WATKINSON, A.R. \& HARPER, J.L. 1978. The demography of a sand dune annual: Vulpia fasciculata. I: The natural regulation of populations. Journal of Ecology 66:15-33.

WESTELAKEN, I.L. \& MAUN, M.A. 1985. Reproductive capacity, germination and survivorship of Lithospermum caroliniense on Lake Huron sand dunes. Oecologia 66:238-245.

WILSON, D.E. 1977. Ecological observations on the tropical strand plants Ipomoea pes-caprae (L.) R. Br. (Convolvulaceae) and Canavalia maritima (Aubl.) Thou. (Fabaceae). Brenesia 10/11:31-42.

ZAR, J.H. 1999. Biostatistical analysis. Prentice Hall, Upper Saddle River.

ZEDLER, P.H., GUEHLSTORFF, K., SCHEIDLINGER, C. \& GAUTIER, C.R. 1983. The population ecology of a dune thistle, Cirsium rhotophilum (Asteraceae). American Journal of Botany 70:1516-1527.

ZHANG, J. \& MAUN, M.A. 1994. Potential for seed bank formation in seven Great Lakes sand dune species. American Journal of Botany 81:387-394. 